\title{
FEA-Based Design Improvement of Small Scale BLDCMs Considering Magnet Thickness and Pole Embrace
}

\author{
C. Ocak, A. Dalcalı, E. Çelik and D. Uygun
}

\begin{abstract}
This study is concerned with the minimization of cogging torque component, by taking into account magnet thickness and pole embrace value for small power battery-fed brushless DC motors (BLDCMs) with high efficiency and high reliability. Distinct values of magnet thickness and embrace are defined in the specified range for the design and comparatively mentioned in the paper. Depending upon the magnet thickness and pole embrace, the obtained new magnet shapes are modelled on a comparative basis using both analytical approach and finite element analysis (FEA). The BLDCM with low cogging torque and optimal magnet shape is designed by the help of 3D FEA by considering the magnetic flux density distributions. In addition, the magnet shape's effect on the motor parameters such as motor efficiency, output power, and air gap flux density is discussed throughout the paper. The analytical results are verified by the transient FEA.
\end{abstract}

Keywords - Cogging torque, embrace, finite element analysis, magnet thickness.

\section{INTRODUCTION}

BLDCM has a widespread use nowadays for its high efficiency, ease of control and ability to operate for long periods of maintenance-free. This type of motor having a permanent magnet (PM) structure is found attractive in industrial applications due to high torque density. However, cogging torque phenomenon, which is inherently caused by the interaction between the permanent magnets and stator teeth, is a severe problem in such motors. It prevents smooth rotation of rotor and is one of the main factors of torque ripples leading to undesirable torque ripples and noise. Also, this problem limits the use of BLDCM in precise motion control systems and portable applications fed by batteries.

In order to reduce cogging torque, many different techniques can be applied. Some of these are the design of fractional ratio of slots per phase, non-uniformed teeth or magnet, skewing stator stack or magnet, stator tooth with and slot opening shift. Unfortunately, these techniques have a number of practical limitations due to the difficulties in manufacturing and undesirable axial mechanical forces [1]-[9].

Manuscript received Febr. 24, 2017. (Write the date on which you submitted your paper for review.)

C. Ocak is with Vocational College of Technical Sciences, Gazi University, Ankara, 06374 TURKEY. (cemilocak@gazi.edu.tr)

A. Dalcalı is with Department of Electrical and Electronics Engineering, Karabük University, Karabük,78050 TURKEY (ademdalcali@karabuk.edu.tr)

E. Çelik is with Department of Electrical and Electronics Engineering, Gazi University, Ankara 06500 TURKEY. (emrecelik@gazi.edu.tr)

D. Uygun is with Aegean Dynamics Inc. Co., Depark, İzmir 35397 TURKEY. (durmus.uygun@aegeandynamics.com)
This study presents an optimal design having low cogging torque feature using the parametric optimization method of the magnet thickness and pole embrace values. It has shown that with the changes in the magnet thickness and pole embrace, cogging torque component can be reduced successfully as in the conventional method for stator tooth or magnet skewing. Moreover, presented method can be performed without any restriction in practice.

In the study, a highly efficient BLDCM with low vibration and noise resulted from the reduced cogging torque component has been designed for a portable system where the BLDCM is fed from battery, instead of the grid power. All sizing calculations are primarily done for a $20 \mathrm{~W}$ BLDCM. In this regard, basic design outputs such as core dimensions, slot number and dimensions, pole number, winding type and characteristics for the corresponding motor are determined. Then, different magnet thickness and pole embrace values are discussed over the specified motor dimensions and the most popular designs for the rotor structure, which yield low cogging torque, are chosen for different design scenarios via FEA. Afterwards, the study has focused on the selected optimal design and improvements are completed by performing several successive optimizations. For the selected suitable parameters, various optimizations are carried out using the parametric approximation method for magnet thickness and embrace that have a large impact upon the motor performance and production cost. After the successful optimization process, for the parameters, previously selected by the way of comparison, optimal magnet thickness and pole embrace are defined. For the motor under consideration, analytic analysis simulations and 2D\&3D FEA are carried out in ANSYS RMxprt and ANSYS Maxwell, respectively. Simulation results and comparisons between the base design and optimized final one are given in detail in the forthcoming chapters.

\section{Mathematical Model AND OUtPut EQuations}

Electrical machine design commonly begins with the sizing equation given by;

$S=11 \cdot K_{w 1} \cdot \bar{B} \cdot a c \cdot\left(\frac{D}{1000}\right)^{2} \cdot \frac{L}{1000} \cdot n$

where $S$ is apparent motor power in VA, $K_{w 1}$ is the winding factor, $B$ is the specific magnetic loading in tesla, ac is the specific electrical loading in $\mathrm{A} / \mathrm{m}, D$ is stator outer diameter in $\mathrm{mm}, L$ is the stack length of the motor in $\mathrm{mm}$ and $n$ is the rated speed in rpm [10]. On the other hand, radial component of the 
air gap flux density produced by permanent magnet can be expressed with the Fourier series as;

$$
B_{\text {gap }}(\theta, r)=\sum_{n=1,3,5}^{\infty} B_{n}(r) \cos \left(\frac{n p}{2} \theta\right)
$$

where $B_{n}$ is the nth harmonic component of the air gap flux density distribution, $p$ is the pole number, $r$ is the air gap radius and $\theta$ is the angular position of a permanent magnet pole. The matrix form of phase voltage equations of BLDCM can be expressed as;

$\left[\begin{array}{l}u_{A} \\ u_{B} \\ u_{C}\end{array}\right]=\left[\begin{array}{lll}R & 0 & 0 \\ 0 & R & 0 \\ 0 & 0 & R\end{array}\right]\left[\begin{array}{l}i_{A} \\ i_{B} \\ i_{C}\end{array}\right]+$

$$
\left[\begin{array}{ccc}
L-M & 0 & 0 \\
0 & L-M & 0 \\
0 & 0 & L-M
\end{array}\right] \cdot \frac{d}{d t}\left[\begin{array}{c}
i_{A} \\
i_{B} \\
i_{C}
\end{array}\right]+\left[\begin{array}{c}
e_{A} \\
e_{B} \\
e_{C}
\end{array}\right]
$$

As for brushed DC motors, torque and power analysis of BLDCMs can be carried out by using similar energy conversion principles. When the motor is operating, a small amount of power drawn from the supply is spent for power losses while the most is transferred to rotor throughout the air gap. This power is generally called as electromagnetic power and calculated by [10], [11]-[13];

$P_{e}=e_{A} l_{A}+e_{B} l_{B}+e_{C} l_{C}$

Where $e_{A, B, C}$ are the back electromotive forces for each phase. Besides, input power of a BLDCM can be computed by;

$p_{i}=p_{c u}+p_{e}+p_{T}$

Where $P_{T}$ represents switching losses and $P_{c u}$ is stator copper losses. By neglecting mechanical and stray losses, electromagnetic power converted into kinetic energy;

$P_{e}=T_{e} \Omega$

In which $T_{e}$ is defined as electromagnetic torque and $\Omega$ as mechanical angular velocity of the rotation [14]-[15].

\section{DESCRIPTION OF THE ANALYSED MOTOR}

Computer-aided design (CAD) systems are based on the finite element method (FEM) for numerical analysis of the electromagnetic problems [16]-[18]. FEM is a practical, fast and reliable method used to calculate the magnetic fields in electrical machinery [19]-[21].

3D model of the three phase, 6-pole, $20 \mathrm{~W}, 3000 \mathrm{rpm}$ BLDCM of which design and analysis have been achieved is illustrated in Fig 1.

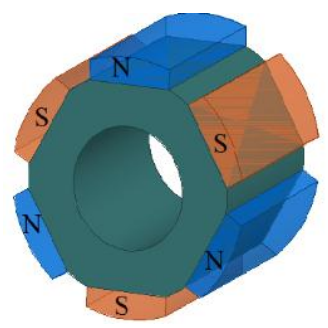

(a)

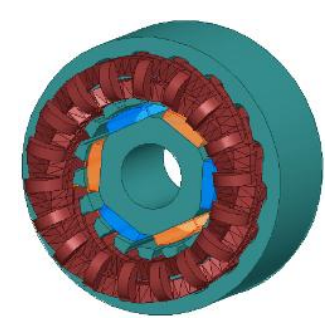

(c)

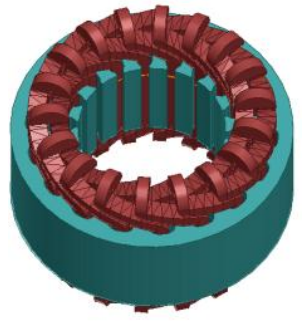

(b)

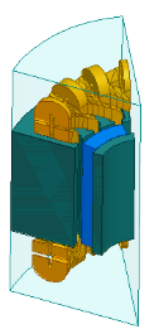

(d)
Fig. 1. 3D BLDCM structure: (a) Rotor, (b) Stator, (c) Complete model, (d) Cut View.

With respect to all parameters calculated by using analytical method, the initial design parameters of the motor are given in Table 1.

TABLE I: INITIAL DESIGN PARAMETERS

\begin{tabular}{ll}
\hline \hline Parameter & Value \\
\hline Stator outer diameter[mm] & 37.7 \\
Length of stator[mm] & 18 \\
Air gap length $[\mathrm{mm}]$ & 0.5 \\
Rotor outer diameter $[\mathrm{mm}]$ & 18.2 \\
Rotor inner diameter $[\mathrm{mm}]$ & 9 \\
Stator material & M270-35A \\
Rotor material & N40SH \\
Number of slots & 18 \\
Pole number & 6 \\
Rated power[W] & \\
\hline \hline
\end{tabular}

\section{COMParative Analysis}

In the study, three different types of surface-mounted motors including the design parameters given in Table 1 are configured and performance analyses are conducted in detail. Therefore, effects of widely used different types of surface-mounted PMs upon the motor design are compared and useful acquisitions are provided for the optimal rotor design criterion. 
TABLE II: THE SELECTION OF OPTIMUM ROTOR STRUCTURE

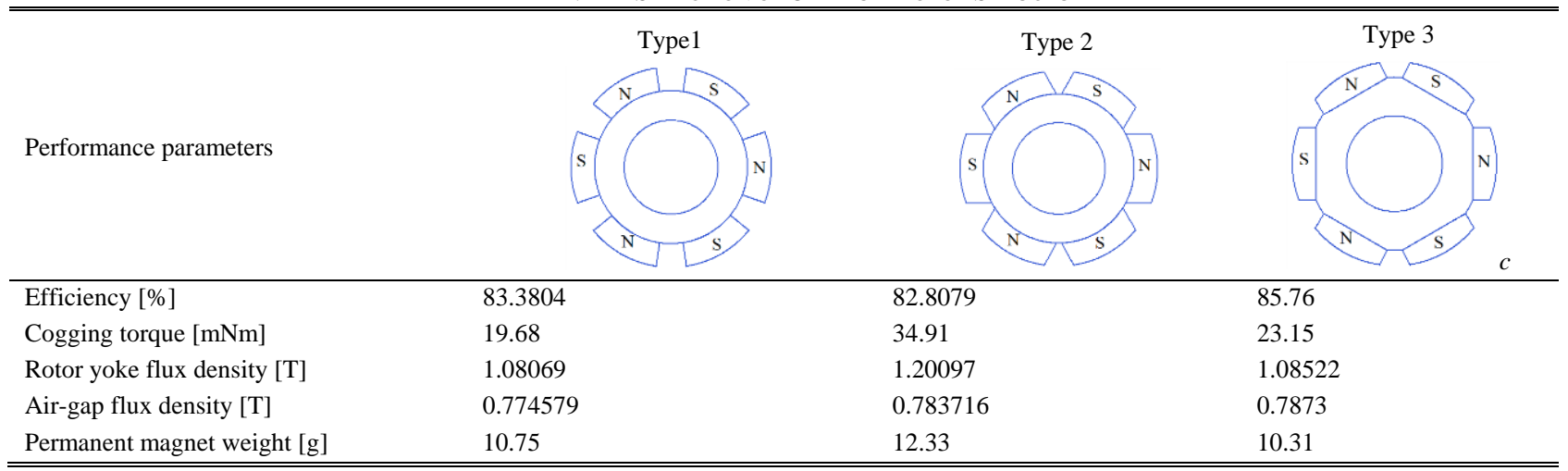

The most crucial factors that should be taken into account for the optimal design can be regarded as high efficiency, low cogging torque component, low volume and low cost. In this context, some performance parameters such as motor efficiency, cogging torque amplitude, amount of magnet usage are investigated and the results are comparatively given in Table 2. During the design process, both airgap flux density and rotor core flux density are kept approximately constant in all three designs in order to make a fair comparison. Through reported results, it is found that Type 2 design yields the lowest efficiency, the highest cogging torque component and maximum magnet consumption when compared to other two designs. Therefore, this rotor-magnet structure has been eliminated for optimal design study. Moreover, in the case that Type 1 and Type 3 are compared, it is shown that cogging torque components are close to each other, but efficiency is higher in Type 3 in which magnet consumption is decreased as well. Owing to these advantages, Type 3 design is selected for the optimal design. Further optimization steps applied to this design will be explained in the next sections.

\section{Optimal Design and Simulation Results}

In this part of the study, optimization studies for Type 3 design selected for the optimal design due to its aforementioned advantages are carried out. During the optimization process, optimal embrace and magnet thickness values will be determined for high efficiency and low cogging torque purposes. As it is known, in PM machine design, pole embrace is a parameter defined as the ratio of magnet arc to pole arc. Accordingly, embrace is closely related to the total amount of magnet use in PM machines. It has also a crucial impact on the cogging torque component. Cogging torque is an undesirable phenomenon owing to the fact that it primarily leads an increase in mechanical vibration and magnetic noise of the machine.

In Type 3 design, embrace and magnet thickness values are analyzed using the parametric approach method by ANSYS RMxprt and Maxwell 2D\&3D software, to reduce the undesirable cogging torque component. In the analysis, the lower limit of the pole embrace is determined as 0.4 while it is 0.8 for upper limit as a result of consideration of physical constraints. The solution step is defined as 0.025 by paying attention to two points: The first is the physical tolerances in magnet production and the latter is that the high sensitivity is desired. There is a trade-off between these two parameters. Similarly, other parametric solution study is conducted for the magnet thickness. The solution range is set between $1 \mathrm{~mm}$ and $3 \mathrm{~mm}$, and the solution step is selected as $0.125 \mathrm{~mm}$.

The resulting cogging torque variation versus embrace and magnet thickness values posterior to performed parametric solutions is demonstrated in Fig. 2. According to Fig. 2, it is clearly seen that the lowest cogging torque component can be obtained when the embrace is very close to 0.7 and the magnet thickness is $1 \mathrm{~mm}$. It should be noted that designer carefully needs to decide what the limits of the solution range should be since the motor power will fall below $20 \mathrm{~W}$ for the magnet thickness value of $1 \mathrm{~mm}$ or less.

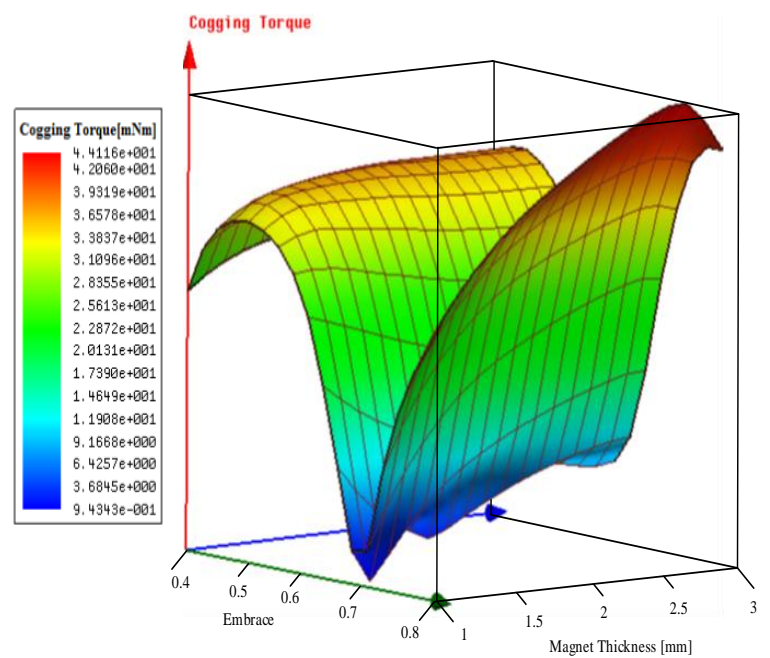

Fig. 2. Cogging torque variation versus magnet thickness and embrace.

During the parametric approach-based process of optimizing the magnet thickness and embrace values, which are initially obtained by the sizing calculations, the region where the efficiency is maximum and the cogging torque is minimum should be considered. But, it may not be always easy to find the parameters (magnet thickness and embrace) that provide maximal efficiency and minimal cogging torque at the same time. In such cases, one should decide by taking into account the priorities in the design. In the cases where the cogging torque can be reduced more below the requested, if the reduced cogging torque value results in reduced efficiency, then new values should be defined, which do not lead the efficiency to drop and can keep the cogging torque within the pre-defined 
limits as well. By means of the performed simulation studies, the magnet thickness and embrace values ensuring the optimal motor design are determined to be $2 \mathrm{~mm}$ and 0.7 , respectively. By using these values in the design, the calculated cogging torque amplitude is $9.484 \mathrm{mNm}$ and the efficiency is obtained as $88.07 \%$.

The new motor design created for the magnet thickness and embrace derived by the optimization is subjected to $2 \mathrm{D}$ and $3 \mathrm{D}$ transient FEM analyses at rated load and rated speed. The resulting magnetic flux density distribution and vector-based representation are given in Fig.3.

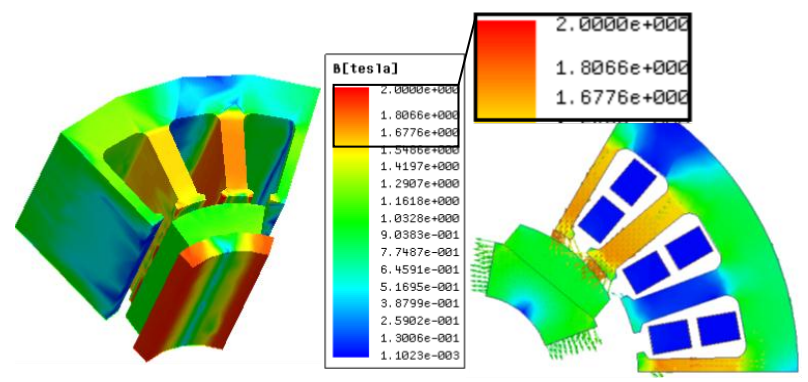

Fig. 3. Motor flux density distributions via 2D\&3D FEM.

As can be seen in Fig.3, maximum flux density in the stator teeth is about $1.71 \mathrm{~T}$, which coincides with the target flux density in sizing calculations. Thus, the motor size is not allowed to enlarge and it is also ensured that the motor does not operate at a flux density close to saturation region. These criteria are essential to examine optimal motor design parameters, meticulously.

The cogging torque variation caused by each magnet thickness value for one mechanical rotation is given in Fig.4. It is clear that the effect of cogging torque is weak in case of smaller magnet thickness values. For this reason, a small value of magnet thickness gives promising results with respect to cogging torque effect. However, it should not be forgotten that motor output power will fall in case of magnet thickness reduction.

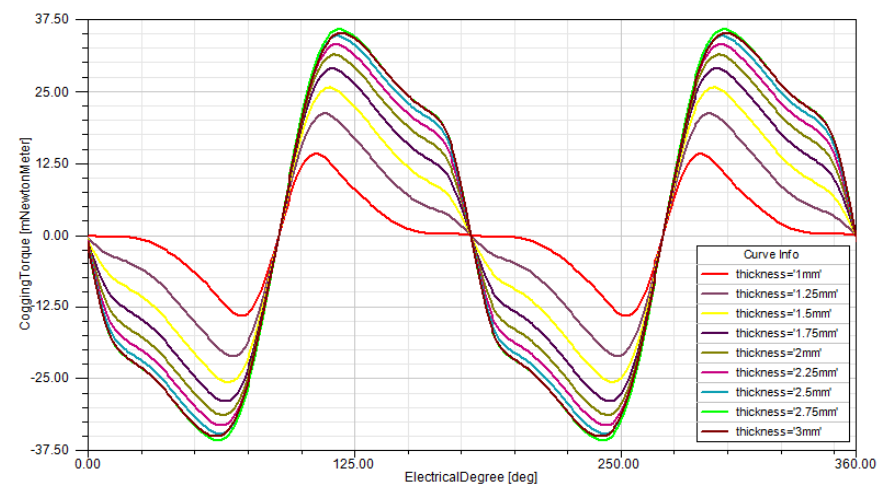

Fig. 4. Variation of cogging torque parameter versus electrical degree for various magnet thickness values.

The performance parameters of Type 3 design before and after the optimization are summarized in Table 3. After optimal design study, motor efficiency is increased from $85.76 \%$ to $88.07 \%$ and cogging torque is decreased from $23.15 \mathrm{mNm}$ to $9.48 \mathrm{mNm}$. Furthermore, magnet consumption is reduced by almost $1.1 \mathrm{~g}$ as compared to the initial design.

TABLE III: Performance PARAMETER VALUes Before AND AFter the OPTIMIZATION

\begin{tabular}{lll}
\hline \hline Parameter & Initial design & Optimal design \\
\hline Cogging torque $[\mathrm{mNm}]$ & 23.15 & 9.48 \\
Efficiency [\%] & 85.76 & 88.07 \\
Total losses [W] & 2.84 & 2.38 \\
Pole embrace & 0.73 & 0.7 \\
Magnet thickness [mm] & 2.2 & 2 \\
Total magnet weight [g] & 10.31 & 9.2 \\
\hline \hline
\end{tabular}

\section{CONCLUSION}

In this study, optimal magnet thickness and pole embrace values have been determined for those of small power battery-fed BLDCMs in order to achieve cogging torque minimization by selecting suitable rotor type. Firstly, performance of the most common 3 different types of surface-mounted motors is investigated step by step by making fair comparisons amongst. Upon decision, once Type 3 design has been chosen due to its better performance, magnet thickness and pole embrace parameters of this design are optimized by parametric solution approach and eventually, the optimal motor design that not only gives minimum cogging torque, but also provides maximum efficiency is achieved. The prominent features of the paper include the minimized cogging torque, decreased total amount of magnet usage and improved motor efficiency. In addition, effects of different rotor types on the motor performance and critical effects of the rotor magnet shapes on motor design are explained throughout the paper. Therefore, it can be concluded that the paper presents a different alternative to motor designers using asymmetrical magnet and slot shapes for the cogging torque minimization and thus facing a set of limitations in production.

\section{REFERENCES}

[1] J. Xintong, X. Jingwei, L. Yong, and L. Yongping, "Theoretical and simulation analysis of influences of stator tooth width on cogging torque of BLDC motors", IEEE Trans. Magn., vol. 45, no. 10, pp. 4601-4604, Oct. 2009.

[2] K. Abbaszadeh and M. Jafari, "optimizing cogging torque reduction in slot opening shift method for BLDC motor by RSM", Proceeding of IEEE 2nd Power Electronics, Drive Systems and Technologies Conference, pp. 62-66, 16-17 Feb. 2011.

[3] Y. Yang, X. Wang, R. Zhang, C. Zhu, and T. Ding, "Research of cogging torque reduction by different slot width pairing in permanent magnet motors", Proceedings of the 8th. International Conference on Elect. Mach. Syst. (ICEMS), vol. 1, pp. 367-370, Sep. 2005.

[4] S. M. Hwang, J. B. Eom, and Y.H. Jung, "Various design techniques to reduce cogging torque by controlling energy variation in permanent magnet motors", IEEE Trans. Magn., vol. 37, no. 4, pp. 2806-2809, Jul. 2001.

[5] C. S. Koh and J. S. Seol, "New cogging-torque reduction method for brushless permanent-magnet motors", IEEE Trans. Magn., vol. 39, no. 6, pp. 3503-3506, Nov. 2003.

[6] G. Xin, H. Guangxian, C. Zhi, and W. Zongpei, "Research of cogging torque in the brushless DC motor with fractional ratio of slots and poles", Proceedings of the 8th. International Conference on Elect. Mach. Syst. (ICEMS), vol. 1, pp. 76-80, Sep. 2005.

[7] C. Breton, J. Bartolome, and J. A. Benito, "Influence of machine symmetry on reduction of cogging torque in permanent-magnet brushless motors", IEEE Trans. Magn., vol. 36, no. 5, pp. 3819-3823, Sep. 2000. 
[8] M. Kitamura, Y. Enomoto, and J. Kaneda, "Cogging torque due to roundness errors of the inner stator core surface", IEEE Trans. Magn., vol. 39, no. 3, pp. 1622-1625, May 2003.

[9] A. Saygın, C. Ocak, A. Dalcalı and M. E. Celik, "Optimum rotor design of small PM BLDC motor based on high efficiency criteria", ARPN Journal of Engineering and Applied Sciences, vol. 10, no. 19, pp. 9127-9132, 2015.

[10] Y. Duan, "Method for Design and Optimization of Surface Mount Permanent Magnet Machines and Induction Machines", Ph.D. thesis, Dept. Electrical and Comp. Eng., Georgia Ins. of Tech., 2010.

[11] A. Saygın, C. Ocak, A. Dalcalı and E. Çelik, "Optimum rotor design of small PM BLDC motor based on high efficiency criteria", presented at the International Conference on Electrical and Electronic Engineering, Melaka, August 2015.

[12] C. L. Xia, Permanent Magnet Brushless DC Motor Drives and Controls, John Wiley \& Sons Publisher, 2012.

[13] A. Saygın, C. Ocak, A. Dalcalı, O. Gürdal, S. Alantar and Y. Tarhan, "Influence of pole arc offset on the field and output parameters of brushless DC motors", Proceedings of Intl. Conf. on Future Trends in Electronics and Electrical Engineering, pp. 16-20, Bangkok, 2013.

[14] J. R. Hendeshot, T. Miller, Design of Brushless Permanent-Magnet Motors, Magna physics publishing and Clarendon press, London, 1994.

[15] H A. Toliyat, G.B. Kliman, Handbook of Electric Motors, CRC Press Taylor \& Francis Group, Boca Raton, 2004.

[16] D. Uygun, S. Solmaz, S. Tozan, A. Turan "A new topology for dual rotor/stator BLDC motors applied to marine thrusters", Proceedings of 4th IEEE International Conference on Power Engineering, Energy and
Electrical Drives (POWERENG'15), pp.353-359, Riga, Latvia, May, 2015.

[17] D. Uygun and S. Solmaz "Design and dynamic study of a $6 \mathrm{~kW}$ external rotor permanent magnet brushless DC motor for electric drivetrains", Proceedings of 4th IEEE International Conference on Power Engineering, Energy and Electrical Drives (POWERENG'15), pp. 87-92, Riga, Latvia, May, 2015.

[18] D. Uygun, S. Solmaz and Y. Cetinceviz "Dual stator/rotor brushless DC motors: a review of comprehensive modelling based on parametric approach and coupled circuit model", Proceedings of 2015 Intl Aegean Conference on Electrical Machines \& Power Electronics (ACEMP), 2015 Intl Conference on Optimization of Electrical \& Electronic Equipment (OPTIM) \& 2015 Intl Symposium on Advanced Electromechanical Motion Systems (ELECTROMOTION), pp. 635-641, Antalya, 2015.

[19] S. L. Ho and W. N. Fu, "Review and future application of finite element methods in induction motors", Electric Machines \& Power Systems, vol. 26 no. 2, pp. 111-125, 2007.

[20] K. G. Upadhyay, Design of Electrical Machines, New age International Limited Publisher, New Delhi, 2008.

[21] O. Maloberti, R. Figueredo, C. Marchand, Y. Choua, D. Condamin, L. Koblylanski and E. Bomme, "3D-2D dynamic magnetic modeling of an axial flux PM motor with soft magnetic composites for hybrid electric vehicles", IEEE Transactions on Magnetics, vol. 50, no. 6, pp. 1-10, 2014. 